\title{
Developmental Anatomy of Zucchini Leaves with Squash Silverleaf Disorder caused by the Silverleaf Whitefly
}

\author{
Judy G. Schmalstig ${ }^{1}$ and Heather J. McAuslane \\ Department of Entomology and Nematology, University of Florida, Gainesville, FL 32611-0620
}

Additional INDEX words. Cucurbita pepo, genetic silvering

\begin{abstract}
Aвstract. Squash silverleaf (SSL) is a physiological disorder of vegetables in the genus Cucurbita L. caused by feeding of nymphs of the silverleaf whitefly (SLW) (Bemisia argentifolii Bellows \& Perring). SSL causes a silvering of the leaves and a blanching of fruit. Leaf silvering is caused by developmental separation of the upper epidermis and the palisade mesophyll layer resulting in additional air space and altered light reflection. The anatomical development of SSL was analyzed in young leaves of zucchini squash (Cucurbita pepo L.) using two susceptible genotypes ('Elite' and YSN347-PMR) and two tolerant genotypes (ZUC76-SLR and ZUC33-SLR/PMR). SLW nymphs were allowed to feed only on the mature leaves and the anatomy of the developing leaves was observed by light microscopy and transmission electron microscopy. Silvering began at the apex of young leaves and developed basipetally. The increased percentage of air space that resulted between the upper epidermis and palisade layers was the result of an increase in the duration of air space development in young, developing leaves. Chloroplasts in silvered tissue of mature leaves and in tissue of young leaves that later became silvered, were smaller and contained less starch than chloroplasts in tissue from noninfested plants. In contrast, development of genetic silvering, a condition not related to whitefly feeding, occurred throughout the entire leaf at one time, beginning as yellowed tissue in the axils of leaf veins then turning silver. Chloroplasts were normal in genetically silvered tissue of genotype YSN421-PMR. The SSL-tolerant genotype, ZUC76-SLR, did not show alteration in chloroplast structure or air space development when challenged with SLW; however, it had shorter and paler petioles, as did the susceptible genotypes. SSL symptoms were induced with spraying of gibberellic acid synthesis inhibitor chlormequat chloride in SSL-susceptible but not in SSL-tolerant genotypes. Reciprocal grafting between susceptible and tolerant plants showed that tolerance resides in the developing tissue and not the mature tissue on which the whiteflies feed.
\end{abstract}

Squash silverleaf (SSL) is one of several physiological disorders caused by feeding of the silverleaf whitefly (SLW) [Bemisia argentifolii (formerly known as Bemisia tabaci Gennadius, B strain) (Perring et al., 1993)]. SSL was first reported in southern Florida in 1987 on acorn squash and zucchini squash (Cucurbita реро) (Simons et al., 1988). It now occurs in vegetable of the genus Cucurbita wherever SLW is found. SSL is characterized by a silvering of the upper leaf surface along the veins in lightly infested plants and over the entire surface of the leaf in heavily infested plants (Jimenez et al., 1995; Schuster et al., 1991; Simons et al., 1988). The fruit become blanched and in severe cases unmarketable (Simons et al., 1988). Other physiological disorders caused by the SLW include irregular ripening of tomato (Lycopersium esculentum Mill.), streaking of pepper (Capsicum annuит L.) fruit, and broccoli white stem in members of the Brassicaceae. All of the disorders are developmental in nature, that is, affecting developing leaves, stems, or fruit and all have an inhibitory effect on pigment production, either chlorophyll or carotenoids, or both (Shapiro, 1995).

Immature SLW nymphs and not the winged adults are responsible for SSL symptoms (Costa et al., 1993; Schuster et al., 1991; Yokomi et al., 1990). SLW is responsible for transmitting several damaging viruses (Costa and Brown, 1991; Hiebert et al., 1995). However, most researchers have ruled out a viral cause of SSL

Received for publication 7 Sept. 2000. Accepted for publication 20 May 2001 Florida Agricultural Experiment Station journal series no. R-07687. This research was supported by USDA grant 9803603 awarded to J.G.S. We thank Deborah Boyd for rearing the whiteflies and Karen Kelley for doing the thin sectioning, sample preparation, and photographing of the TEM sections. The cost of publishing this paper was defrayed in part by the payment of page charges. Under postal regulations, this paper therefore must be hereby marked advertisement solely to indicate this fact.

${ }^{1}$ Currently associate professor, Department of Biology, Rollins College, Winter Park, FL 32789. because there is no supporting evidence. Specifically, no doublestranded RNA has been detected in the affected leaves (Cohen et al., 1992; Jimenez et al., 1994; Yokomi et al., 1990). Further, there was no transmission of SSL from SSL-affected leaves grafted to whitefly-free plants and no mechanical transmission (Yokomi et al., 1990). As final evidence, when whitefly nymphs are killed or infested leaves removed, new growth is normal (Yokomi et al., 1990).

The cause of the silver appearance of the leaf in whitefly-induced SSL is separation of the upper epidermis from the palisade mesophyll resulting in altered reflection of light (Jimenez et al., 1995). The same separation was seen in silvered leaves of $C$. pepo in Israel and was reportedly associated with drought (Burger et al., 1988). The altered palisade air space structure appears to be a developmental abnormality because only those leaves forming during whitefly feeding are affected (Schuster et al., 1991; Yokomi et al., 1990). Once a leaf is silver, it remains silver. However, if whiteflies are removed from the plant, leaves formed after removal develop normally. If the whitefly nymphs are confined to mature leaves, only the newly formed leaves show the symptoms. These patterns of development and the appearance of silvering first along the secondary veins suggest that some translocated factor moves from the infested leaves via the phloem to the apical meristem and the developing leaves (Yokomi et al., 1990).

In addition to the abnormal development of the upper epidermis/mesophyll space, chlorophyll levels are lowered by as much as $40 \%$ to $50 \%$ by whitefly feeding (Jimenez et al., 1995; Yokomi et al., 1995). Feeding by the sweetpotato whitefly (Bemisia tabaci biotype A) also results in lowered chlorophyll levels but not to as great an extent as the SLW (Jimenez et al., 1995). Increased light reflectance and reduced chlorophyll could be responsible for a reduction in photosynthesis. SLW does reduce photosynthetic 
rates in cotton (Gossypium hirsutum L.) (Lin et al., 1999) and tomato (Buntin et al., 1993), but no data have been reported for squash.

Our goal was to study further the developmental anatomy of SSL in young leaves of susceptible zucchini squash plants and compare that to development in SLW-challenged tolerant plants and plants showing genetic silvering or chemical induction of silvering symptoms. We used two genetic lines that do not develop SSL underSLW population levels found in the field, ZUC76-SLR and ZUC33-SLR/ PMR (McAuslane et al., 1996). Previous research to distinguish antixenosis, antibiosis, and tolerance showed that lack of symptoms in these lines is due to tolerance (Cardoza et al., 1999). The silver appearance of SSL leaves due to the epidermis and palisade separation is similar to genetic silvering common in squash and other plants, except that in genetic silvering, the silver appearance occurs in the axils of the leaf veins. Gibberellic acid (GA) synthesis inhibitors, chlormequat chloride, and paclobutrazol, induced leaf silvering, which was reversed in part by spraying with GA, suggesting that altered hormone levels may be involved in SSL (Yokomi et al., 1995)

\section{Materials and Methods}

Plant And insect material. Zucchini seeds were germinated in 48 cell $\left(144 \mathrm{~cm}^{3}\right)$ flats filled with Metromix (Grace Seirra, Milpitas, Calif.). When the first true leaf appeared, seedlings were transplanted into 5.7-L clay pots with a medium of 1 pasteurized sand : 3 peat lite soil mix (Conrad Fafard, Agawan, Mass.) (by volume) in a greenhouse in Gainesville Fla. (Cardoza et al., 1999). Plants were fertilized weekly with $100 \mathrm{~mL}$ of a $3.4 \mathrm{~g} \cdot \mathrm{L}^{-1}$ solution of a $20 \mathrm{~N}-8.8 \mathrm{P}-16.6 \mathrm{~K}$ water soluble fertilizer (W.R. Grace, Fogelsville, Pa.). Greenhouse lighting was natural and reached a maximum of $2000 \mu \mathrm{mol} \cdot \mathrm{m}^{-2} \cdot \mathrm{s}^{-1}$. Temperatures in the greenhouse varied between 20 to $40{ }^{\circ} \mathrm{C}$. Susceptible C. pepo genotypes used were 'Elite', YSN347-PMR, and YSN421-PMR. Some 'Elite' plants showed genetic silvering and those plants were not used. YSN347-PMR exhibited no genetic silvering and YSN421PMR consistently showed genetic silvering in the leaf axils. Tolerant breeding lines used were ZUC76-SLR and ZUC33-SLR/PMR, neither of which showed any genetic silvering. 'Elite' was purchased from Harris Seeds, Rochester, N.Y. The other breeding lines were obtained from R.B. Carle, Mid-Florida Research and Education Center, Apopka, Fla. SLWs were reared in the laboratory on cotton and collard [Brassica oleracea L. (Acephala Group)] as described by Cardoza et al. (1999).

SLW INFESTATION, PLANT GROWTH, AND SSL GRADES. Twenty-five adult mating pairs of SLW were aspirated from the colony plants into a clip cage made from $25-\mathrm{mL}$ plastic vials $(27 \mathrm{~mm}$ in diameter $\times 50 \mathrm{~mm}$ in height). Two cages per plant were clipped onto the abaxial surface of the second to fourth oldest leaves of plants ( 2 to 2.5 weeks old) in the greenhouse. After $3 \mathrm{~d}$, the clip cages were removed and any surviving whiteflies were aspirated from the plant. Control plants had clip cages without SLWs. About $8 \mathrm{~d}$ after adding the adult whiteflies, eggs hatched and crawlers were observed and began feeding within $24 \mathrm{~h}$. All leaves were numbered beginning with the oldest leaf as number one. Lengths of all young, growing leaves were measured daily starting on the day SLWs were added till the end of the experiment, $\approx 3$ weeks. At the end of the experiment, leaves were removed and final leaf length and lamina area were measured with a portable leaf area meter (LI-3000A; LI-COR, Lincoln, Nebr.). Petiole length was also measured. Experiments to provide material for observation of symptoms, measurement of leaf length, and tissue for anatomical study, were conducted three times over a 6-month period. Each experiment had 10 susceptible plants of each genotype and 10 tolerant plants, five of each type with SLW and five without SLW. Means of lamina length, petiole length, and duration of leaf initiation for SLW-infested plants and plants without SLW were compared by an unpaired $t$ test of two samples assuming equal variances using Microsoft Excel 97 SR-2 software (Microsoft Corp., Redmond, Wash.).

Severity of SSL symptoms was rated as described by Paris et al. (1987) with the following grades: $0=$ leaves with no SSL symptoms; $1=$ leaves with silvering in and parallel to less than half of the veins; $2=$ leaves with silvering in and parallel to more than half of the veins; $3=$ leaves with silvering in and parallel to all of the veins; $4=$ leaves with silvering in all veins and some interveinal areas; and $5=$ with the entire upper surface silvered. Leaf silvering first occurred the apices of developing leaves. The percentage of leaf silvering was measured as the length of leaf tissue exhibiting any degree of silvering divided by the total length of the leaf. Analysis of the relationship of percentage of silvering from the apex as a function of leaf length was performed by linear regression analysis using Microsoft Excel 97 SR-2 software (Microsoft Corp.).

Photosynthesis AND TRANSPIRATION. Net carbon exchange rate (NCER) and transpiration were measured in an open-system photosynthesis system (Model CI-301PS; CID, Inc., Vancouver, Wash.). Measurements were taken on 'Elite' leaves that were 8.5 to $10 \mathrm{~cm}$ long, free of adult and immature whiteflies, and were exhibiting grade 5 SSL symptoms. Measurements were also taken on leaves from whitefly-free plants that showed no SSL symptoms. Part of one leaf was enclosed in a $6.25-\mathrm{cm}^{2}$ chamber. Carbon dioxide concentration entering the chamber was 380 to $390 \mu \mathrm{L} \cdot \mathrm{L}^{-1}$. Three measurements per leaf were taken at each of 12 irradiances ranging from 5 to $2000 \mu \mathrm{mol} \cdot \mathrm{m}^{-2} \cdot \mathrm{s}^{-1}$. Maximum ambient greenhouse irradiance was 1800 to $2000 \mu \mathrm{mol} \cdot \mathrm{m}^{-2} \cdot \mathrm{s}^{-1}$, but NCER was measured at $1000 \mathrm{HR}$ when irradiance was $\approx 1200 \mu \mathrm{mol} \cdot \mathrm{m}^{-2} \cdot \mathrm{s}^{-1}$. To obtain a range of irradiances, natural light was supplemented with a fiber optic lamp and was reduced with neutral density filters placed over the leaf chamber.

Preparation of Tissue for microscopy.Leaf tissue was sampled from whole plants between 0900 to 1000 HR over several days. Samples were taken from leaves before symptoms were evident and the plants were returned to the greenhouse and scored for SSL as symptoms developed. Leaf pieces $\left(2 \mathrm{~mm}^{2}\right)$ were cut from attached leaves and placed immediately into fixative containing $3 \%$ glutaraldehyde, 2\% formaldehyde, $130 \mathrm{~mm}$ sucrose, and Aerosol OT (Fisher Scientific, Pittsburgh, Pa.) surfactant in sodium-phosphate buffer, $\mathrm{pH}$ 7.2. Solid Aerosol OT was allowed to dissolve into the fixation solution from a dissecting needle coated with the solid surfactant. Gentle suction was applied to the samples in a 5-mL syringe. Samples remained in fixative for $3 \mathrm{~h}$, were rinsed five times with sodium-phosphate buffer with sucrose over $2.5 \mathrm{~h}$, and were post-fixed in $2 \%$ osmic acid overnight at $4{ }^{\circ} \mathrm{C}$ with $100 \mathrm{~mm} \mathrm{NaCl}$. The following day, tissue was warmed slowly to room temperature and then rinsed four times in sodium-phosphate buffer with $100 \mathrm{~mm}$ $\mathrm{NaCl}$ over $2 \mathrm{~h}$. Tissue was dehydrated in a series of nine grades of ethanol (20\% to $100 \%)$ and then acetone over $5 \mathrm{~h}$ and embedded in Spurr's resin. Samples for transmission electron microscopy (TEM) were sectioned with a diamond knife and poststained with $2 \%$ uranyl acetate and Reynold's lead citrate. Specimens were viewed with a Hitachi H-7000 transmission electron microscope (Hitachi, Ltd., Tokyo, Japan). Samples of the above described tissue embedded in Spurr's resin were also viewed by light microscopy by cutting $1-\mu \mathrm{m}$-thick sections with a glass knife and staining them with methylene blue. 


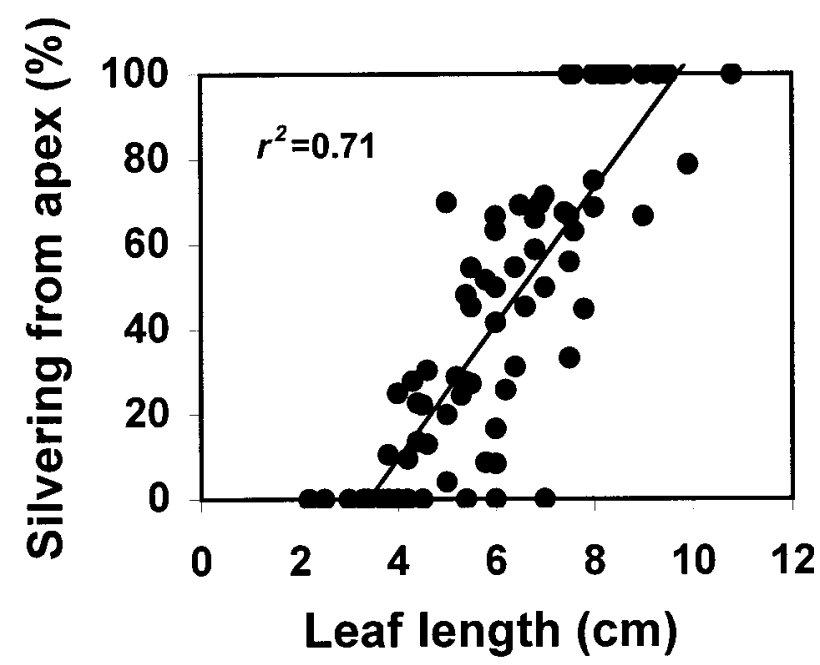

Fig. 1. Percentage of a leaf of 'Elite' zucchini squash showing silvering symptoms from the apex as a function of leaf length. Leaves first showed silvering in the apex followed by progressive development of symptoms throughout the entire lamina. Each point represents one leaf of a particular length. Line was determined by linear regression analysis.

AnAlysis OF CELl NUMBERS AND DIMENSIONS. Leaf length was used as a measure of leaf age. Daily measurement of leaf length demonstrated that growth of individual plants was similar and that the presence of SLW did not affect the rate of leaf growth or the duration between leaf initiations. Leaf initiation times were measured as the time in days for consecutive leaves to reach $2 \mathrm{~cm}$ in length. Leaves of 'Elite' ranging in length from 1.5 to $10 \mathrm{~cm}$ (with $10 \mathrm{~cm}$ being the maximum, nonexpanding length) were sampled. In addition, mature silvered and control leaves of the same age from 'Elite' and YSN347-PMR plants free of SLW were sampled. Leaf tissue samples of the developmental series and mature leaves were prepared as described in preparation of tissue for microscopy. Cross-sections of the samples were viewed digitally at $20 \times$ with a professional digital camera (Pixera, Los Gatos, Calif.) attached to a compound microscope. The number of epidermal and palisade cells per millimeter was counted, and the length and section area of palisade cells, the total area of the leaf section, and the area occupied by air spaces were measured. The area occupied by vascular bundles was subtracted from the total area for calculations of percentage air space. The imaging program ImagePC (Beta Version 1, Scion Corp., Frederick, Md.) was used to analyze the cross-sections. All dimensions were averages of at least 100 cells from several different tissue blocks from one leaf. The relationships between leaf length and air space percentage, and between leaf length and epidermal : palisade cell numbers were analyzed by linear regression analysis using Microsoft Excel 97 SR-2 software. Means of the length and area of upper palisade cells, and the percentage of air space in the palisade and spongy mesophyll were compared between SLWinfested plants and plants without SLW by an unpaired $t$ test of two samples assuming equal variances in Microsoft Excel 97 SR-2.

Grafting. Reciprocal grafting of susceptible ('Elite' and YSN347-PMR) and tolerant (ZUC76-SLR andZUC33-SLR/PMR) plants was performed using plants with five to seven leaves. The stock had at least two mature leaves on which SLWs were eventually caged. The scion was an apical shoot tip with several attached young leaves that were $<2 \mathrm{~cm}$ in length. Matching V-cuts were made in the stock and scion and were held together with surgical tape. The grafted plants were kept individually in perforated plastic bags (Ziploc, DowBrands, Indianapolis, Ind.) for several days to main- tain high humidity during formation of the graft unions. A single clip cage with 25 pairs of adult SLWs was attached to each of the two mature leaves of the stock plant after the graft union was established and the scion was forming new leaves. Cheesecloth was placed over the scion leaves to prevent oviposition by any escaped adult whiteflies. All scion leaves were evaluated for SSL and checked for nymphs under a dissecting microscope. If the scion leaves had SLW, then that plant was not included in the anaylsis. In several grafted plants, axillary leaf buds of the stock leaves broke and the developing leaves served as an internal control.

Ga SYNTHESIS INHIBITORS. An aqueous solution of chlormequat chloride (CCC) (Cycocel, American Cyanamid, Wayne, N.J.) at $1000 \mathrm{mg} \cdot \mathrm{L}^{-1}$ was sprayed to runoff on mature leaves or the young apex of 'Elite' and ZUC76-SLR. Control plants were sprayed to runoff with $1 \%(\mathrm{v} / \mathrm{v})$ Tween 20 . Experiments were conducted twice with five plants of each genotype in both the control and CCC treatments. In other experiments, the growing medium in the pots was drenched with $180 \mathrm{~mL}$ of an aqueous solution of CCC at 3000 $\mathrm{mg} \cdot \mathrm{L}^{-1}$ or with $180 \mathrm{~mL}$ of $1 \%(\mathrm{v} / \mathrm{v})$ Tween 20 . These experiments were conducted twice with five plants of each genotype as above in each treatment.

\section{Results}

DEVELOPMENTAL AND GROWTH EFFECTS OF SLW. Leaf silvering in susceptible zucchini squash genotypes occurred 3 to $4 \mathrm{~d}$ after SLW crawlers were observed on the mature leaves, as reported previously (Cardoza et al., 1999). The first one or two leaves to show symptoms generally had only yellow veins or silvering along the major veins (grade 1). Many of these leaves had silvering only in the basal part of the leaf. The second or third and all subsequent leaves to show symptoms developed the maximum rating of that plant (grade 3 to 5).

For leaves that developed SSL symptoms, the developmental age at the time of initial induction was measured as the leaf length within a 24-h time period after the first crawlers were observed. After crawlers emerge from the eggs, they move around the leaf searching for a suitable place to insert their stylets. Previous work showed that only $24 \mathrm{~h}$ of nymphal feeding is necessary to induce silvering in developing leaves (Cardoza, 1998). Leaves that developed grade 4 to 5 silvering throughout the lamina were 1.5 to $2.5 \mathrm{~cm}$ long at the time of crawler emergence. Leaves that were 2.6 to 4.0 $\mathrm{cm}$ in length developed grade 1 to 2 silvering in the basal areas only. Leaves 4.5 to $6.0 \mathrm{~cm}$ long at the time of crawler emergence developed yellow veins only, and leaves $>6 \mathrm{~cm}$ did not develop symptoms. (All data are ranges of leaves sampled from 11 plants for each genotype).

In leaves that eventually developed silvering throughout the whole lamina, the silvering of veins and interveinal areas first appeared at the apex of leaves when they were $\approx 4 \mathrm{~cm}$ long or $40 \%$ of the final laminar length (FLL) (Figs. 1 and 2). Over the next $2 \mathrm{~d}$, silvering developed in a basipetal fashion, reaching the base of a lamina when the leaves were $\approx 8.5 \mathrm{~cm}$ long or $85 \%$ FLL in both 'Elite' and YSN347-PMR. Leaves $\approx 6 \mathrm{~cm}$ long had silvering symptoms in the apical half of the leaf only (Fig. 2).

The tolerant genotype, ZUC76-SLR, did not show any leaf silvering at the whitefly densities used in these experiments. Neither the susceptible nor the tolerant lines had reduced lamina lengths or significant changes in the time between initiation of new leaves at the apical meristem in response to SLW (Table 1). However, both susceptible and tolerant lines had reduced petiole lengths in response to SLW (Table 1). The petioles also appeared lighter green 

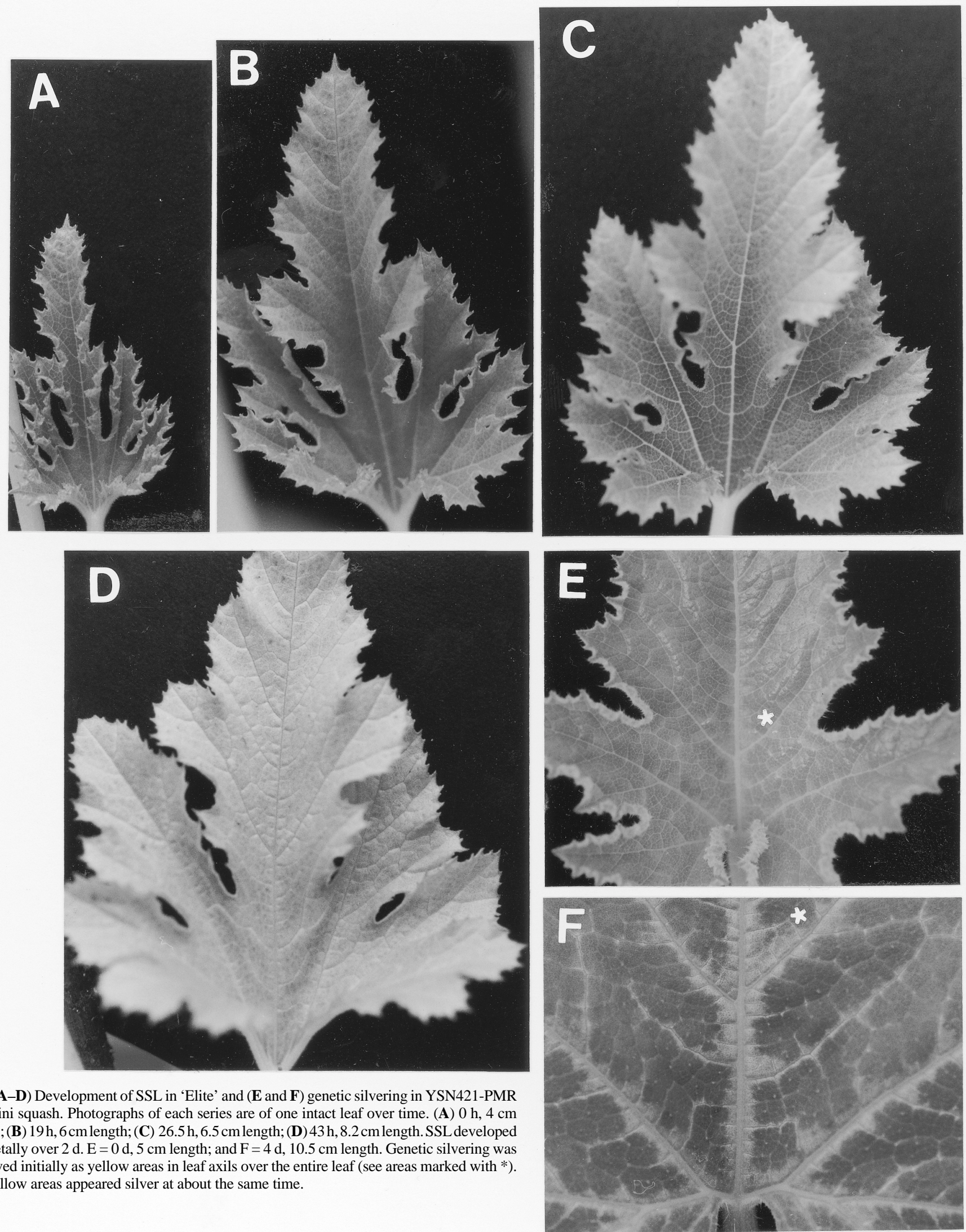

Fig. 2. (A-D) Development of SSL in 'Elite' and ( $\mathbf{E}$ and $\mathbf{F})$ genetic silvering in YSN421-PMR zucchini squash. Photographs of each series are of one intact leaf over time. (A) $0 \mathrm{~h}, 4 \mathrm{~cm}$ length;(B) 19h, $6 \mathrm{~cm}$ length;(C) $26.5 \mathrm{~h}, 6.5 \mathrm{~cm}$ length;(D) $43 \mathrm{~h}, 8.2 \mathrm{~cm}$ length. SSL developed basipetally over $2 \mathrm{~d} . \mathrm{E}=0 \mathrm{~d}, 5 \mathrm{~cm}$ length; and $\mathrm{F}=4 \mathrm{~d}, 10.5 \mathrm{~cm}$ length. Genetic silvering was observed initially as yellow areas in leaf axils over the entire leaf (see areas marked with *). All yellow areas appeared silver at about the same time. 
Table 1. Lamina and petiole length $(\mathrm{cm})$ for leaves numbered 8 to 10 (leaf number 1 being oldest) and time between initiations of leaves for leaves numbered 7 to 10 as affected by silverleaf whitefly (SLW) in susceptible, 'Elite', and tolerant, ZUC76-SLR, zucchini squash genotypes. Leaves 7 to 10 , for + SLW treatment, developed while the SLW were feeding on mature leaves. Values are means of 10 plants with SDs in parentheses.

\begin{tabular}{|c|c|c|c|c|c|c|}
\hline \multirow{2}{*}{$\begin{array}{l}\text { Genotype } \\
\text { and leaf no. }\end{array}$} & \multicolumn{2}{|c|}{ Lamina length $(\mathrm{cm})$} & \multicolumn{2}{|c|}{ Petiole length $(\mathrm{cm})$} & \multicolumn{2}{|c|}{ Leaf initiation (d) } \\
\hline & $-\mathrm{SLW}$ & + SLW & - SLW & $+\mathrm{SLW}$ & $-\mathrm{SLW}$ & + SLW \\
\hline \multicolumn{7}{|l|}{$\overline{\text { Elite }}$} \\
\hline 8 & $9.7(0.31)$ & $9.0(0.58)^{\mathrm{z}}$ & $17.0(2.3)^{* * *}$ & $13.6(1.9)^{* *}$ & $2.4(0.94)$ & $2.7(0.94)$ \\
\hline 9 & $8.3(0.22)$ & $7.9(1.2)^{\mathrm{z}}$ & $13.2(1.8)^{* *}$ & $10.2(1.9)^{* *}$ & & \\
\hline 10 & $7.6(0.42)$ & $6.3(0.91)^{\mathrm{z}}$ & $10.7(2.7)^{* * *}$ & $6.3(1.3)^{* * *}$ & & \\
\hline \multicolumn{7}{|l|}{ ZUC76-SLR } \\
\hline 8 & $7.9(0.51)$ & $7.8(0.29)$ & $14.8(2.6)^{* * *}$ & $11.2(0.76)^{* *}$ & $1.8(0.76)$ & $2.1(0.67)$ \\
\hline 9 & $7.5(0.66)$ & $7.5(0.31)$ & $13.4(0.99)^{*}$ & $10.0(0.75)^{*}$ & & \\
\hline 10 & $7.1(0.66)$ & $6.4(0.68)$ & $10.6(0.89)^{*}$ & $8.2(0.41)^{*}$ & & \\
\hline
\end{tabular}

${ }^{\mathrm{z}}$ Leaves had grade 5 silvering.

*,** Significant at $P<0.01$ or 0.005 , respectively. Means of lamina and petiole length with or without SLW for each numbered leaf were compared by an unpaired $t$ test assuming equal variances.

in color in both susceptible and tolerant lines when challenged with SLWs.

Photosynthetic and transPirational effects of SLW. Transpiration with increasing irradiance was not different in SLWinduced grade 5 leaves of 'Elite' compared to control leaves (Fig. $3 \mathrm{~A})$. However, grade 5 leaves had a $30 \%$ reduction in the maximum NCER (Fig. 3B). Light saturation was reached at $700 \mu \mathrm{mol} \cdot \mathrm{m}^{-2} \cdot \mathrm{s}^{-1}$ in grade 5 leaves, but not until 1000 to $1200 \mu \mathrm{mol} \cdot \mathrm{m}^{-2} \cdot \mathrm{s}^{-1}$ in control leaves. Ambient light in the greenhouse during the experiment $(1000 \mathrm{HR})$ on a cloudless day was $\approx 1200 \mu \mathrm{mol} \cdot \mathrm{m}^{-2} \cdot \mathrm{s}^{-1}$.

ANATOMICAL AND ULTRASTRUCTURAL EFFECTS OF SLW. The silver appearance of leaves was the result of additional air space formation between the upper epidermis and the upper palisade mesophyll (Fig. 4A and B) as described previously (Jimenez et al., 1995; Ramos et al., 1995). Mature grade 5 leaves of YSN347-PMR, but not 'Elite', had smaller palisade cells both in length and area (Table 2, Fig. 6A and B) and as a result were thinner than control leaves. Mature grade 5 leaves of both YSN347-PMR and 'Elite' had a greater percentage of air space in both the palisade and spongy mesophyll areas (Table 2).

Internal anatomy was studied as leaves developed from $1.5 \mathrm{~cm}$ to mature nonexpanding leaves at $10 \mathrm{~cm}$. Leaves that eventually exhibited silvering through the lamina (grade 5) only began to show silvering in the apex when they were 4 to $6 \mathrm{~cm}$ long (Figs. 1 and 2) and provided good material with which to compare recently silvered tissue to tissue about to develop symptoms. Cross-sections of apical and basal lamina regions showed that separation of the upper epidermis and the upper layer of palisade cells, which is responsible for the observed silver appearance, occurred as normal air spaces were developing (Figs. 4 and 5). The apical areas of 6-cm leaves already showed a separation of the upper epidermis and the upper palisade (Fig. 4B) and had $15 \%$ to $20 \%$ air space as measured from cross-sections (Fig. 5A). The basal areas showed no symptoms and had $<5 \%$ air space. Air space development in the apical regions of leaves from noninfested plants continued until the leaves were $6 \mathrm{~cm}$ (Fig. 5A). No further increase occurred even though leaf area increased. However, in leaves from SLW-infested plants, the percentage air space continued to increase throughout leaf expansion, resulting in a larger percentage air space in mature silvered leaves compared to controls (Fig. 5A). It should be pointed out that the larger percentage air space in SSL was not only in the palisade layer, but also in the spongy mesophyll (Table 2).

One explanation for cell layer separation in genetic silvering is that the upper epidermis and palisade layers are expanding at different rates in silvered areas and therefore a separation occurs (Jimenez et al., 1995). To test this possible cause in SLW-induced silvering, the number of upper epidermal and upper palisade cells per millimeter in leaf cross-sections was measured in leaves of different ages. There was no difference in the ratio of epidermal cell number to palisade cell number for the SLW-infested and noninfested leaves of 'Elite' as the leaves developed (Fig. 5B). In both, this ratio appears close to $1: 1$.
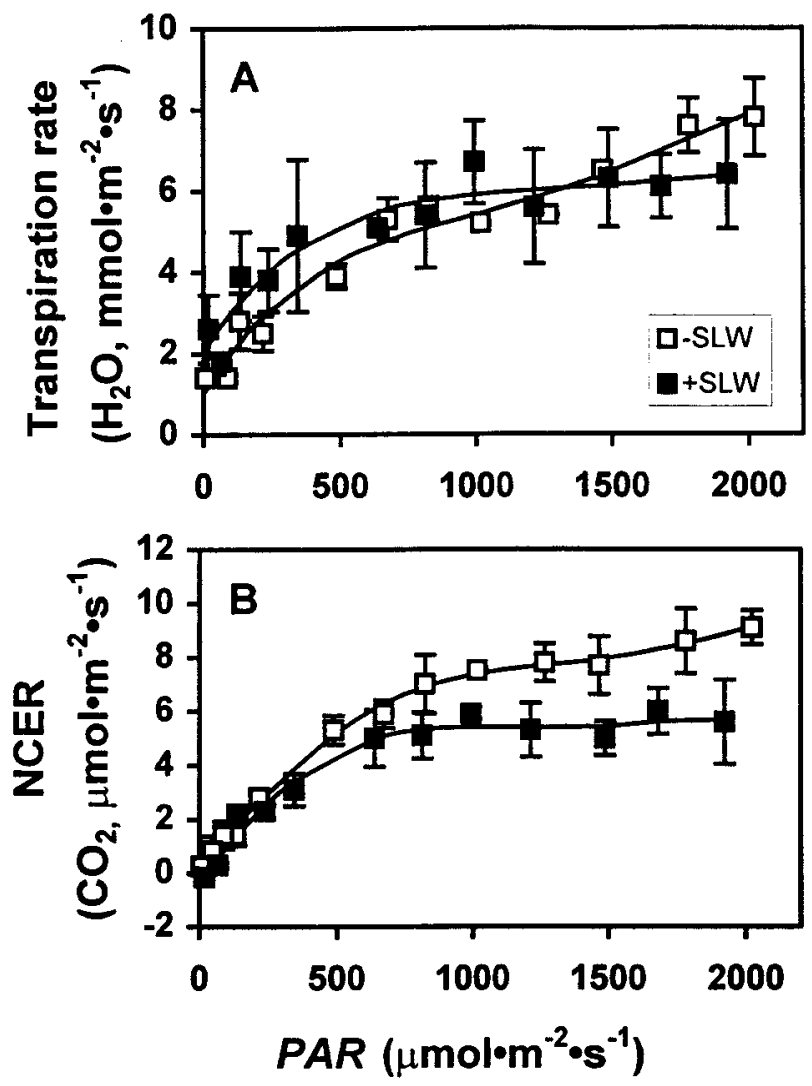

Fig. 3. (A) Transpiration and (B) net carbon exchange rate (NCER) as a function of photosynthetically active radiation $(P A R)$ of SSL leaves, grade 5 , induced by SLW $(+$ SLW) compared to leaves from plants with no SLW (-SLW). Portions of leaves were enclosed in a chamber connected to an open system supplied with $\mathrm{CO}_{2}$ at 380 to $390 \mu \mathrm{mol} \cdot \mathrm{mol}^{-1}$. Each symbol is the mean of three measurements of each of three leaves. Vertical bars $=$ SD. Curves are polynomials fitted to the data. 
Increased air space in leaves that developed during SLW feeding, also meant that there was less contact between epidermal and palisade cells and between palisade cells (Fig. 4) (Jimenez, et al. 1995; Ramos, et al., 1995). Upper palisade and epidermal cells from leaves with SSL were either not touching or were touching only at one point, compared to the majority of cells in control leaves in which the entire short side was abutting the epidermis (Fig. 4). As a result, control palisade cells were more rectangular in shape than cells from SSL-affected leaves.

TEM revealed that chloroplasts of all mesophyll cells of SSLaffected leaves were smaller and had less starch accumulation than those of nonaffected leaves (Figs. 6 and 7). Previous work with pumpkin (Cucurbitapepo) also revealed deformed chloroplasts, but normal starch accumulation, in some of the palisade mesophyll cells of SSL-affected leaves (Jimenez et al., 1995). Palisade cells in mature leaves with SSL had the same number of chloroplasts, but they appeared smaller and had smaller starch granules compared to control leaves (Fig. 6). In grade 5 leaves of YSN347-PMR the palisade cells were not as expanded as controls and had smaller vacuoles.

Chloroplasts were smaller in leaves that showed no outward symptoms, but developed SSL as they matured. Smaller chloro-
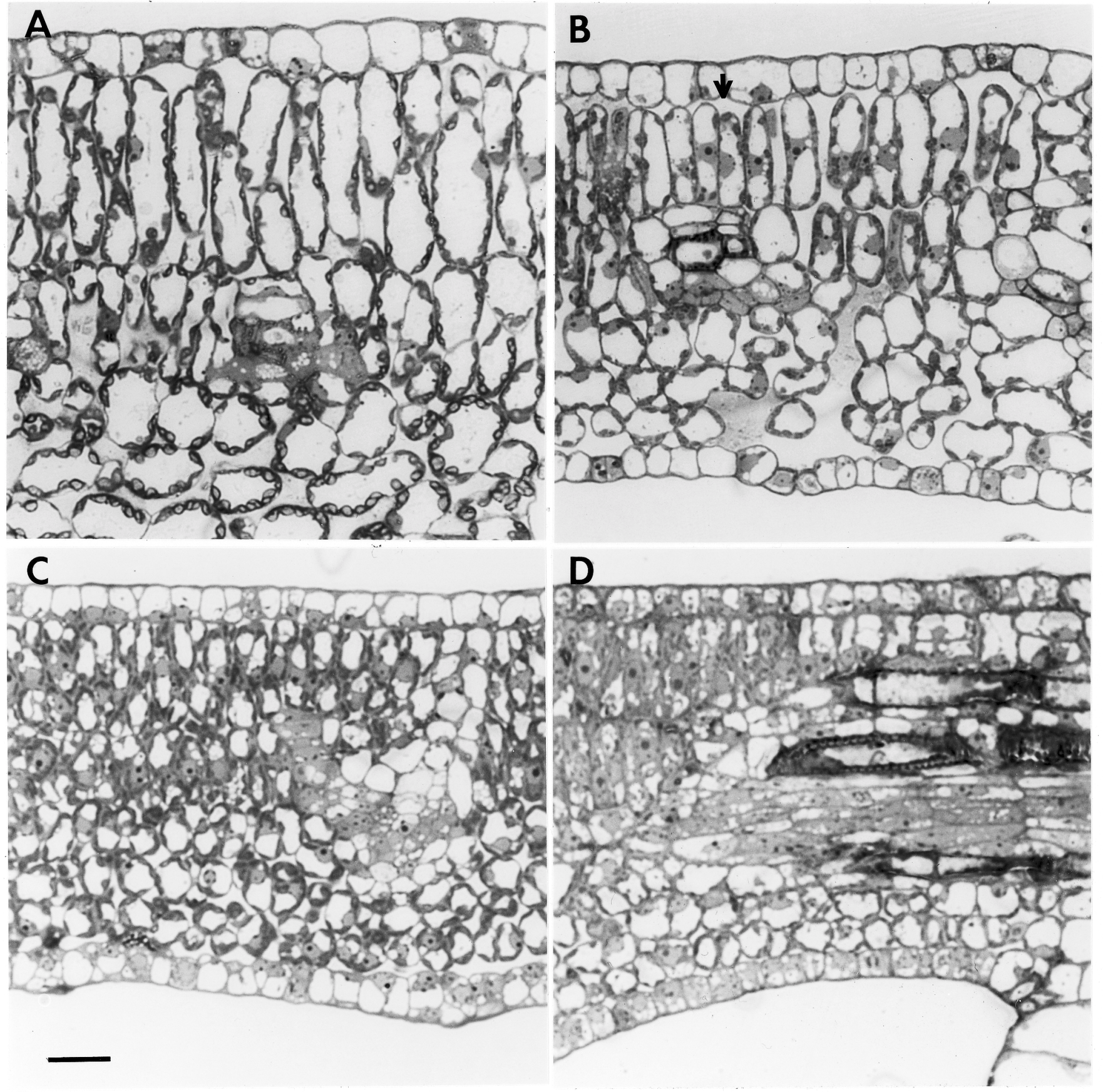

Fig. 4. Photomicrographs of cross-sections from the (A and $\mathbf{B})$ apex and $(\mathbf{C}$ and $\mathbf{D})$ base of 'Elite' zucchini squash leaves $6 \mathrm{~cm}$ in length from plants infested with $(\mathbf{B}$ and D) or (A and C) without SLW. Separation of the upper epidermis and upper palisade cells in SSL is marked with an arrow in B. Beginning of normal air space development can be seen in the basal sections (C and D). External morphology of a similar leaf can be seen in Fig. 2B. TEM sections from the basal area can be seen in Fig. 7D. Scale bar $($ shown in $\mathbf{C})=18 \mu \mathrm{m}$. 
Table 2. Size of cells and percentage of air space in mature leaf cross-sections of 'Elite' and YSN347-PMR zucchini squash plants as affected by SLW. Leaves from +SLW treatment all developed while SLW were feeding on mature leaves. Data are means of six sections from three leaves. Each section was $\approx 0.03 \mathrm{~mm}^{2}$ and contained 250 to 300 cells. SDs are shown in parentheses.

\begin{tabular}{|c|c|c|c|c|}
\hline Genotype & $\begin{array}{l}\text { Length upper } \\
\text { palisade }(\mu \mathrm{m})\end{array}$ & $\begin{array}{c}\text { Area upper } \\
\text { palisade }\left(\mu \mathrm{m}^{2}\right)\end{array}$ & $\begin{array}{c}\text { Air space } \\
\text { palisade }(\%)\end{array}$ & $\begin{array}{c}\text { Air space spongy } \\
\text { mesophyll }(\%)\end{array}$ \\
\hline \multicolumn{5}{|l|}{ YSN347 } \\
\hline$-\mathrm{SLW}$ & $40.2(2.1)^{* *}$ & $514(39)^{* *}$ & $6.6(0.73)^{*}$ & $13.5(1.02)^{*}$ \\
\hline$+\mathrm{SLW}^{\mathrm{z}}$ & $27.9(1.9)^{* *}$ & $305(27)^{* *}$ & $9.1(0.84)^{*}$ & $18.0(1.54)^{*}$ \\
\hline \multicolumn{5}{|l|}{ Elite } \\
\hline$-\mathrm{SLW}$ & $57.0(1.8)$ & ND & $7.8(0.99)^{*}$ & $9.7(0.89)^{*}$ \\
\hline$+\mathrm{SLW}^{\mathrm{z}}$ & $55.9(1.2)$ & ND & $11.1(0.56)^{*}$ & $13.1(0.81)^{*}$ \\
\hline
\end{tabular}

${ }^{\mathrm{z} L e a v e s ~ h a d ~ g r a d e ~} 5$ silvering.

*,** Significant at $P<0.02$ or 0.00001 , respectively. Means for each genotype with or without SLW were compared by an unpaired, two sample $t$ test assuming equal variances.

plasts with smaller starch grains were seen in the basal areas of $6-\mathrm{cm}$ leaves that showed silvering only in the apical regions (Fig. 7C and D). Even in leaves only $2 \mathrm{~cm}$ in length, before any symptoms were seen, smaller chloroplasts with smaller starch grains were evident (Fig. 7A and B).

There were no visible differences in chloroplast size and starch accumulation in leaves of tolerant plants that developed with SLW on mature leaves or in silvered versus nonsilvered areas of genetically silvered plants (electron micrographs not presented). In leaves developing from plants treated with CCC, chloroplasts were normal in size and starch accumulation was much greater than that of controls, with the starch grains accounting for $>90 \%$ of the transectional area of the chloroplast (electron micrographs not presented).

Grafting OF SUSCEPTIBLE AND TOLERANT PLANTS. Reciprocal grafts between susceptible and tolerant plants revealed that tolerance of ZUC76-SLR was in the young leaves and not in the mature leaves on which the SLWs were feeding. When SLWs were placed on the susceptible stock, the tolerant scion developed no symptoms (grade 0 for 16 leaves from three successful grafts), however, developing leaves from axillary buds of the susceptible stock developed SSL. However, when SLWs fed on the tolerant stock leaves, the developing leaves of the susceptible scion showed SSL symptoms (grade 4 for 15 leaves from three successful grafts).

COMPARISON OF CCC-INDUCED SILVERING, GENETIC SILVERING, AND SSL. Treatment of 'Elite' with CCC either to mature leaves only, young apex only, or to the soil caused leaves that developed after treatment to silver with grades of $4,4.5$, and 4.5 , respectively (mean of 12 plants, each with 3 to 4 silvered leaves). The treated leaves had yellow areas, particularly along the margins, and parts that turned brown and dried. The newly developed leaves, in addition to silvering, were darker green as reported previously (Yokomi et al., 1995) and had shorter petioles (+CCC, $9.4 \mathrm{~cm}, \mathrm{SD}=3.4 ;-\mathrm{CCC}, 19.0$ $\mathrm{cm}, \mathrm{SD}=3.6)$. Spraying of SSL-tolerant plants with CCC did not cause leaf silvering, but reduced petiole length by $50 \%$ (+CCC, 9.0 $\mathrm{cm}, \mathrm{SD}=1.1 ;-\mathrm{CCC}, 18.6 \mathrm{~cm}, \mathrm{SD}=2.8$ ).

Development of CCC-induced silvering began 3 to $4 \mathrm{~d}$ after treatment and proceeded basipetally, as did SLW-induced silvering. The cause of silvering was also a separation of the epidermis from the upper palisade cells as determined by light microscopy. However, development of genetic silvering was not like CCC or SLWinduced silvering. The location of silvering in genetically silvered leaves was in the angle between the branching of the larger veins (Fig. 2E and F). Genetically silvered leaves of YSN421-PMR showed the beginnings of this silvering throughout the whole lamina at the same time. Areas that eventually appeared silver were first visible as yellow areas. As the leaves matured the yellow areas silvered (Fig. 2E and F).

\section{Discussion}

SSL symptoms in the leaf occur distant from the feeding of the SLWs and appear only as the leaf matures. Maturity of dicot leaves follows a basipetal direction, with the apex maturing first in terms of vascular structure, capacity for photosynthesis, commencement
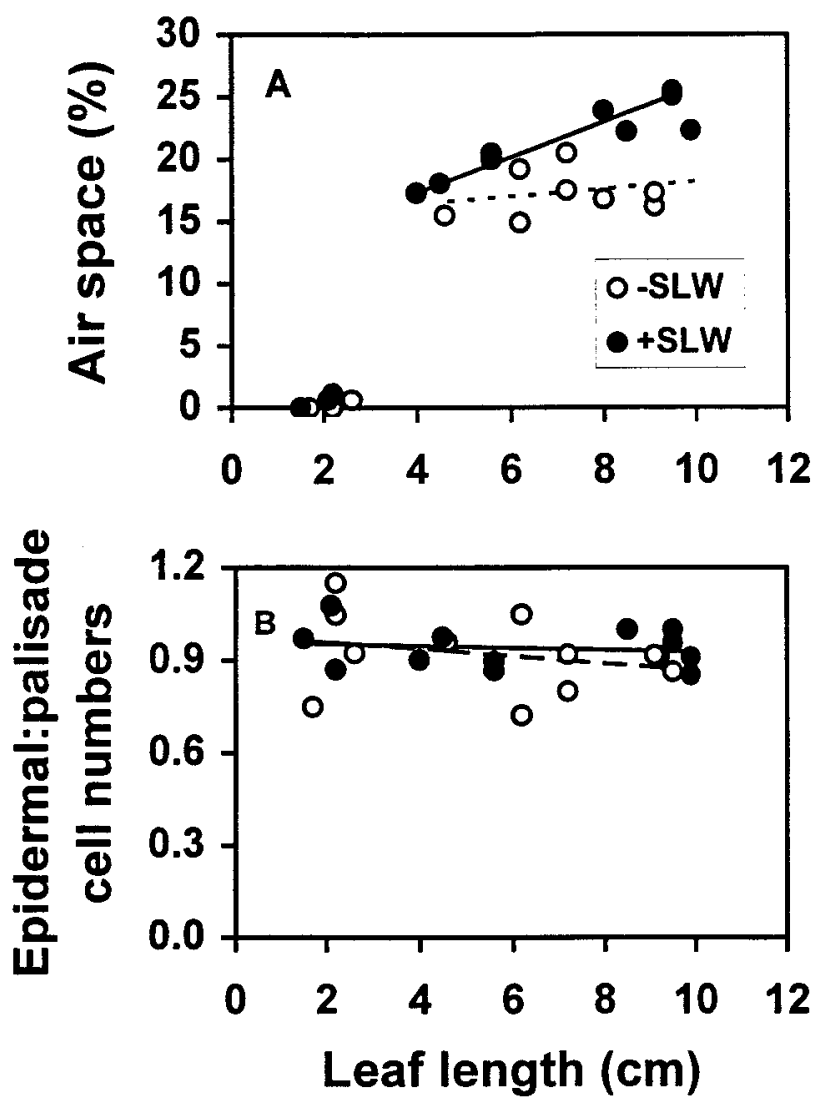

Fig. 5. (A) Percentage air space and (B) ratio of epidermal cell number to palisade cell number as a function of leaf length of 'Elite' zucchini squash as affected by SLW. (A) Air space percentage is of the total cross-sectional leaf area minus the venal area. (B) Ratio of epidermal cell number to palisade cell number is per millimeter of the upper leaf surface. Each symbol represents the mean of three sections from the apical area of one leaf. Each section was an area of $\approx 0.03 \mathrm{~mm}^{2}$ and contained 250 to 300 cells. Lines were determined using linear regression analysis. 
of phloem export, and development of air spaces (Dale and Milthorpe, 1983; Isebrands and Larson, 1973; Turgeon and Webb, 1973, 1975). Thus, it was not surprising that silvering of leaves also began at the tip of the lamina and proceeded basipetally (Fig. 2). Silvering was first seen in the apex of leaves $\approx 4 \mathrm{~cm}$ long. This was the same time that air spaces began to develop in the apex of leaves from both control and SLW-infested plants (Fig. 5B) and as reported in the literature for squash (Turgeon and Webb, 1975). Leaf silvering induced by CCC, a GA-synthesis inhibitor, also developed basipetally. However, development of genetic silvering did not develop basipetally. Genetic silvering developed initially as yellow areas in
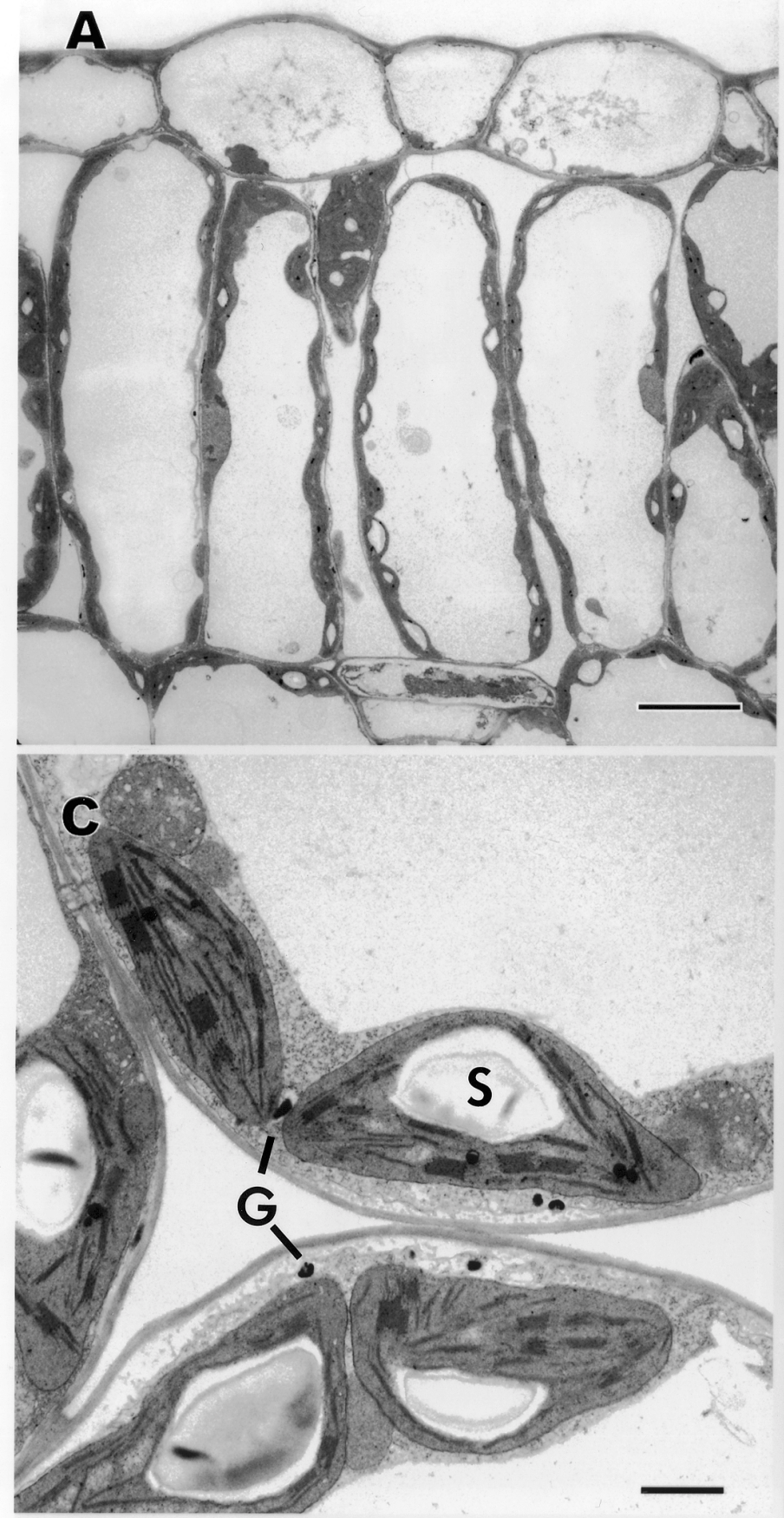

the axils of leaf veins and the silvering of such areas appeared across the entire lamina at the same time. Therefore, the epidermal and palisade layer separation in genetic silvering must be occurring after normal air space development.

Current understanding of air space development is that it occurs schizogenously at junctions between three contiguous cells. Jeffree et al. (1986) found an electron-dense osmiophilic body in these junctions in bean (Phaseolus vulgaris L.) leaves. In the present study, such electron-dense bodies can be seen in the youngest leaves (Fig. 7A and B). Jeffree et al. (1986) hypothesize that cell wall degradation is an important process in formation of air spaces in

\section{B}
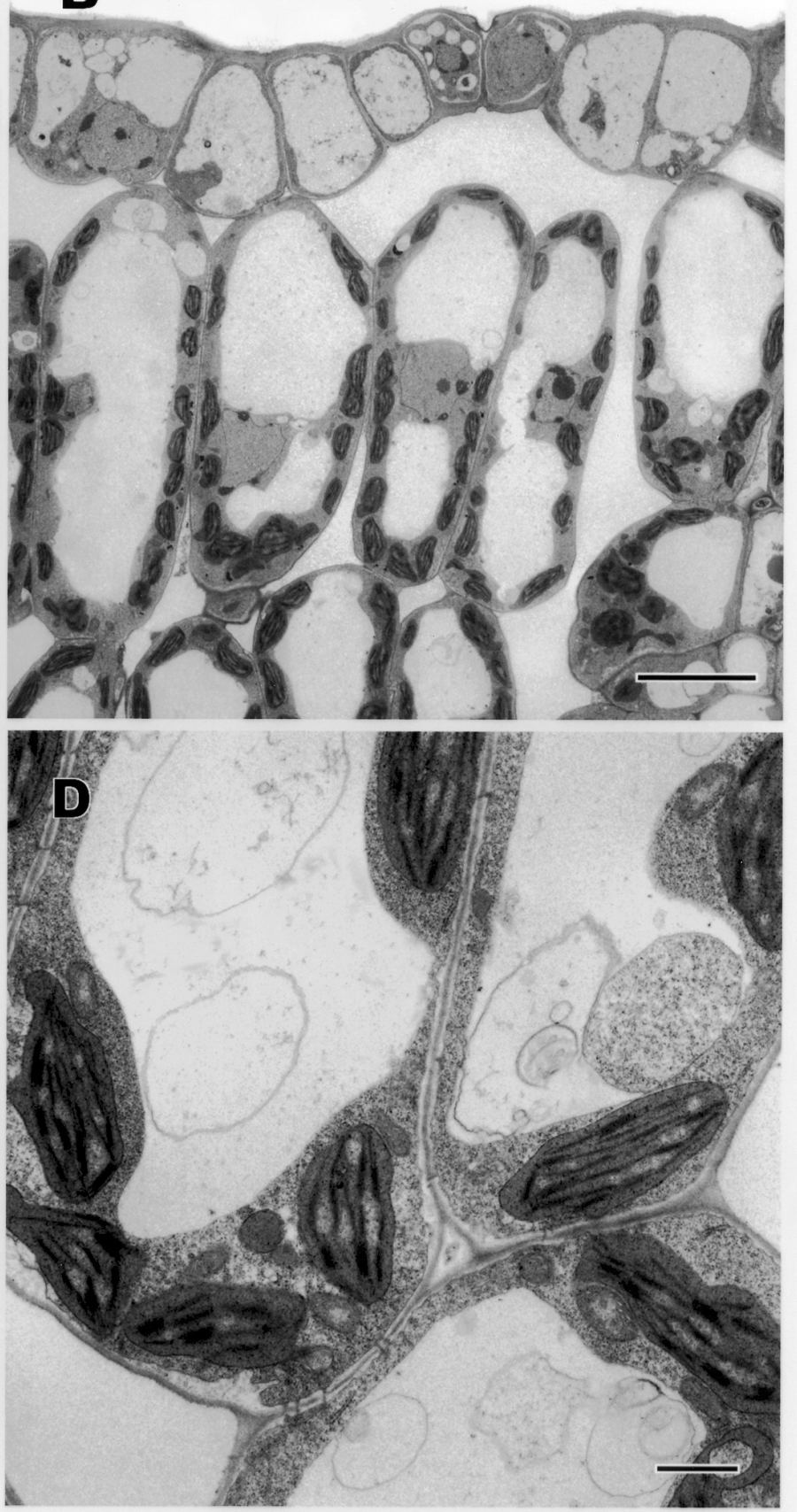

Fig. 6. Transmission electron micrographs of upper epidermis and upper palisade tissue of matureYSN347-PMR zucchini squash leaves without SLW (A and C) and mature grade 5 leaves (B and D). C and D are higher magnifications of other regions of the sections shown in A and B, respectively. In C the large white areas within the chloroplasts are starch grains (S) and the dark, osmiophilic granules (G) seen in cytoplasm of both SSL and normal leaves are probably damage to leaves from daily water stress. In $\mathrm{A}$ and $\mathrm{B}$, scale bars $=4 \mu \mathrm{m}$ and in $\mathrm{C}$ and $\mathrm{D}$, scale bars $=1 \mu \mathrm{m}$. 
addition to continued cell enlargement of the epidermis. They observed in scanning electron micrographs, remnants of cell wall material as intercellular scalariform strands connecting palisade cells. There was no evidence of mechanical damage of cells that would result from a pulling apart of mesophyll cells as the epidermis expands.

It has been suggested that cell separation in SSL and genetic silvering results from altered cell expansion of epidermis and palisade layers causing a separation of the two layers (Jimenez et al., 1995). However, in light of the aforementioned ideas about normal intercellular air space formation, we wanted evidence for the mechanism of cell separation. If the additional air space between the epidermis and palisade layer in SSL was the result of more rapid cell expansion rate of one of the layers, then buckling might be expected with evidence of mechanical damage. No such evidence was observed in our material. Further, if there was an altered rate of cell expansion in the lateral direction, the ratio of epidermal to upper palisade cells should have been altered in leaves from SLW-infested plants. However, the ratio was constant throughout leaf development and was not significantly different between leaves from control or SLW-infested plants. Therefore, increased cell separation was most likely a result of increased or prolonged cell wall degra-
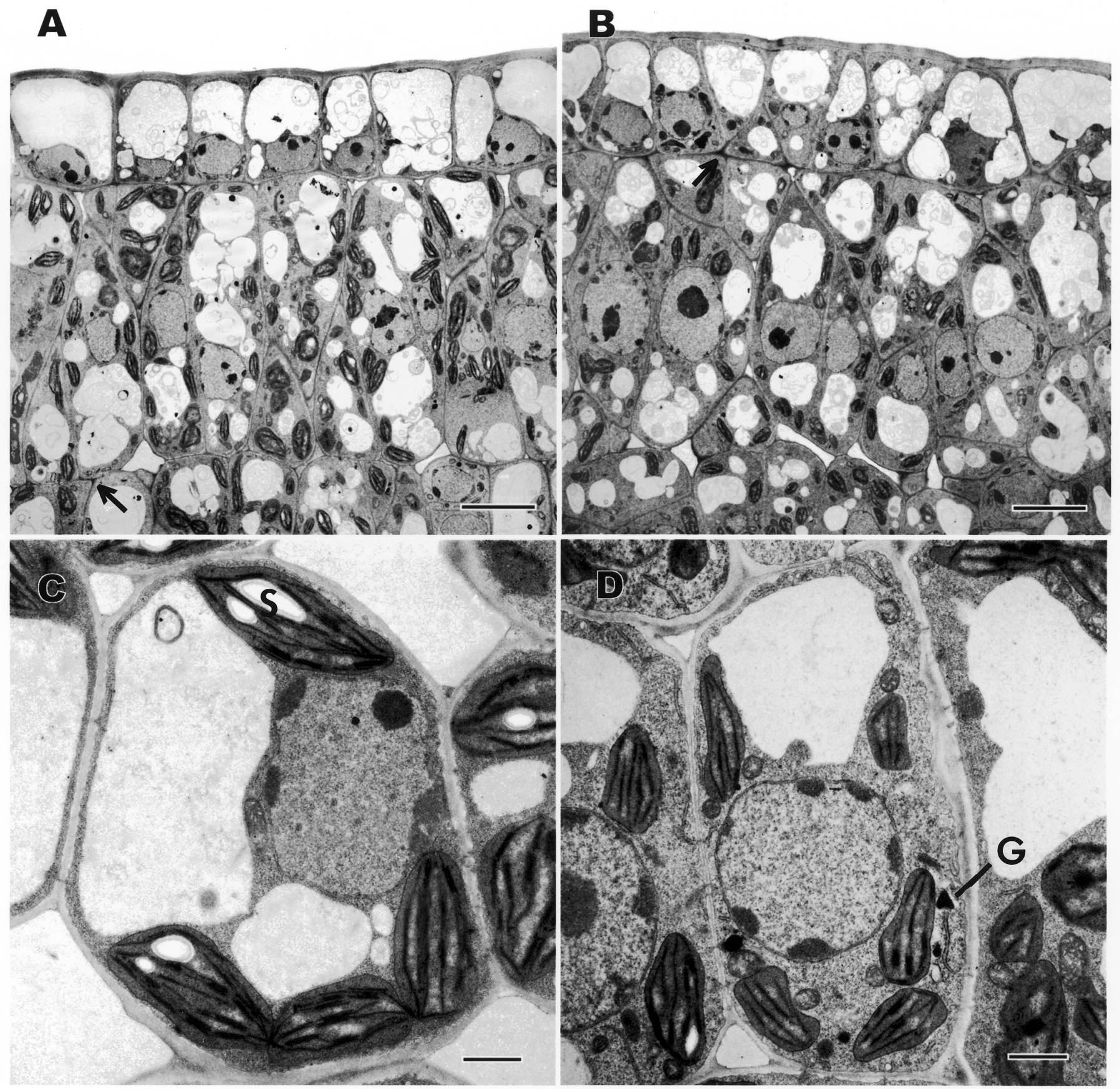

Fig. 7. Transmission electron micrographs of developing leaves of 'Elite' zucchini squash before leaf silvering was visible. (A) Control and (B) +SLW are from leaves $2 \mathrm{~cm}$ in length. Many small vacuoles are seen and the chloroplasts are already smaller in size. (C) Control and (D) + SLW are from the basal area of leaves $6 \mathrm{~cm}$ in length. Arrows in A and B indicate electron-dense bodies at the junction of three or four cells where intercellular air spaces would have developed. In D chloroplasts from leaves with SLW are smaller and have less accumulated starch (S) than leaves from noninfested plants (C). In D the dark, osmiophilic granules (G) seen in cytoplasm of both SSL and normal leaves are probably evidence of damage to leaves from daily water stress. In A and B, scale bars $=4 \mu \mathrm{m}$ and in C and D, scale bars $=1 \mu \mathrm{m}$. 
dation. A prolonged time of air space development was observed in SSL-affected leaves. Percentage air space in the palisade and spongy mesophyll areas continued to increase as long as the leaf was expanding, in contrast to control leaves in which there was no further increase in percentage air space after leaves were $\approx 50 \%$ expanded.

Homopteran insects are known to release middle lamella- and cell-wall-degrading enzymes such as pectinesterase, polygalacturonase, and cellulase during stylet probing and phloem feeding (Adams and McAllan, 1958; Campbell and Dreyer, 1985; Laurema and Nuorteva, 1961). However, existence of such enzymes in SLW has not been demonstrated. Even if SLW saliva contained appreciable amounts of pectic enzymes, it seems unlikely that cell wall degradation in the developing leaves results from such enzymes traveling in the phloem. First, the enzymes would have to be translocated in the phloem and then exit the sieve elements in the developing leaves. Second, increased cell wall degradation occurs only at a precise time in leaf development. In pumpkin leaves with SSL, two new intercellular proteins were detected by SDS-polyacrylamide gel electrophoresis (Jimenez et al., 1995). Perhaps these proteins are involved in altered cell wall degradation. A recent report showed that RNA for a $\beta$-glucosidase-like protein is induced in silvered leaves in response to SLW but not to the closely related sweetpotato whitefly, though the RNA is induced by both whiteflies in the infested leaves (van de Ven et al., 2000). The authors state that it is not clear if this induced transcript is related to insect defense or to development of silvering.

The smaller size of chloroplasts and lack of starch accumulation in SSL-affected leaves were striking. There is considerable communication from the nucleus to the chloroplast, as many of the chloroplast proteins are translated from mRNA transcribed from DNA in the nucleus. Recently, evidence has been found for communication in the other direction, from chloroplast to nucleus (Brutnell and Langdale, 1998). Specifically, there are several mutations that affect chloroplast development and result in altered palisade layer development, the same situation seen in SSL. The differentiation and greening locus in snapdragon (Antirhinum majus L.) blocks chloroplast development, resulting in white areas of the leaf with green revertant areas. The white areas have palisade cells reduced in length (Chatterjee et al., 1996). The defective chloroplasts and leaves gene in tomato also affects chloroplast development, causing white leaf tissue and palisade cells that do not expand to form their normal columnar shape (Keddie et al., 1996). The pale cress mutant of Arabidopsis thaliana (L.) Heynh. prevents normal chloroplast development and in later leaf expansion results in increased air space in the palisade mesophyll, making it indistinguishable from spongy mesophyll (Reiter et al., 1994). All three of the aforementioned reports suggest that normal chloroplast development is necessary for palisade development. Based on the nature of these mutants and the fact that reduced chloroplast size was the first observation of any change in leaves developing SSL, we suggest that whatever is translocated from the SLW-infested leaves to developing leaves affects the chloroplast as an early target, and that altered chloroplast development leads to the abnormal cell separation of the epidermis and palisade layer. Tolerant plants that did not show SSL also did not show abnormal chloroplast development. However, genetically silvered areas of the genotype YSN421-PMR tested in this study also did not have altered chloroplast structure, suggesting that the causal mechanism of epidermal separation in genetic silvering is different than that of SSL-induced silvering.

One possible chloroplast pathway that could be involved in SSL is the isoprenoid pathway responsible for synthesis of GA, the phytol side chain of chlorophyll, and carotenoids, such as lycopene in tomato. Shapiro (1995) suggested that this pathway may be involved in SLW-induced irregular ripening of tomato in which lycopene synthesis is disrupted. In developing leaves, carotenoids are used as photoprotectants. Any reduction in carotenoids could result in damage to developing chloroplasts. SSL symptoms are known to be more severe at higher irradiances in both the field (Simons et al., 1988) and laboratory (Cohen et al., 1992). Perhaps inhibition of the latter stages in isoprenoid synthetic reactions could reduce carotenoids and also reduce chlorophyll levels, as reported by Jimenez et al. (1995), and so alter GA levels.

Reduced NCER in completely silvered leaves could result from several factors: increased light reflection from silvered leaves, reduced chlorophyll levels, reduction in stomatal aperture, or inhibition of photosynthetic efficiency other than reduced chlorophyll. Reduced stomatal aperture was probably not the cause because transpiration was not affected by SLW. Increased light reflection from the leaf surface was probably not the sole cause of reduced NCER because reduction was evident only at irradiances $>500$ $\mu \mathrm{mol} \cdot \mathrm{m}^{-2} \cdot \mathrm{s}^{-1}$. Based on disruption of chloroplast development, reduced chlorophyll levels and possible inhibition of the photosynthetic apparatus seem the most likely causes for reduction in NCER.

The tolerant line, ZUC76-SLR, shows true tolerance to SLW feeding (Cardoza et al., 1999). That is, SLW can complete their life cycle on the tolerant lines, but do not induce leaf silvering (though the tolerant lines did have shorter and paler petioles). Our results demonstrate that the tolerance lies within the developing leaves and not within the mature leaves where SLWs are feeding, for the following three reasons. Mature leaves of the tolerant line infested with nymphs showed the same SLW-induced damage as did susceptible genotypes, namely, a 1 to $2 \mathrm{~mm}$ diameter yellow area around each nymph. Secondly, the tolerant line when sprayed with CCC did not show any silvering in the developing leaves, yet the sprayed leaves appeared yellow and stressed as did sprayed leaves of susceptible plants. Thirdly, grafting of tolerant to susceptible genotypes showed no silvering in tolerant developing leaves when grafted to a susceptible stock with mature leaves challenged with SLW. However, in the reverse situation, mature tolerant leaves challenged with SLWs transmitted the signal to developing leaves of susceptible scions. Understanding the genetics of tolerance may reveal the targeted pathways responsible for SSL.

Development of silvering in leaves was consistent with a signal moving in the phloem. Leaves that were 2.6 to $4.0 \mathrm{~cm}$ long at the time of initial SLW feeding developed symptoms only in the basal areas. Such leaves would be expected to be importing from the phloem only in the basal area of the leaves (Turgeon and Webb, 1973). The nature of that signal remains unknown. It has been suggested that the signal is a stress response of the plant, emanates from the whitefly itself, or from endosymbiotic bacteria living in the SLW (Shapiro, 1995). The grafting results were consistent with the signal coming directly from the whitefly or its symbiont. However, it is possible that in the tolerant lines, the leaves on which the SLW are feeding, respond to the insects, and send a signal to the young apex. In normal tolerant plants, that signal does not affect the developing leaves. However, in the grafted plants, the signal from the tolerant leaves could have had an effect on the developing leaves of susceptible plants.

In conclusion, leaf silvering in zucchini squash plants induced by SLW followed a basipetal development from the apex and was visible as normal air spaces developed. However, in SSL-affected leaves, air space development continued throughout leaf expansion, unlike normal leaves in which it stopped when leaves were $50 \%$ FFL. Continued air space development was likely the result of 
continued cell wall degradation and not the result of unequal cell expansion and misalignment between the upper epidermis and upper palisade as the ratio of epidermis to palisade cells remained unchanged in SLW-infested plants. The first observable change in SSL was smaller chloroplasts in leaves not showing outward symptoms. This effect on chloroplast development may be what leads to abnormal cell wall degradation because of disrupted signaling from the chloroplasts to the nucleus of palisade cells. The tolerant line ZUC76-SLR provides excellent material with which to identify the processes affected during leaf development, because the tolerance lies within the developing leaves themselves.

\section{Literature Cited}

Adams, J.B. and J.W. McAllan. 1958. Pectinase in certain insects. Can. J. Zool. 36:305-308.

Brutnell, T.P. and J.A. Langdale. 1998. Signals in leaf development, p. 161-195. In: J.A. Callow (ed.). Advances in botanical research. vol. 28. Academic Press, New York.

Buntin, G.D., D.A. Gilbertz, and R.D. Oetting. 1993. Chlorophyll loss and gas exchange in tomato leaves after feeding injury by Bemisia tabaci (Homoptera: Aleyrodidae). J. Econ. Entomol. 86: 517-522.

Burger, Y., A. Schwartz, and H.S. Paris. 1988. Physiological and anatomical features of the silvering disorder of Cucurbita. J. Hort. Sci. 63:635640.

Campbell, B.C. and D.L. Dreyer. 1985. Host-plant resistance of sorghum: Differential hydrolysis of sorghum pectic substances by polysaccharases of greenbug biotypes (Schizaphis graminum, Homoptera: Aphididae). Arch. Insect Biochem. Physiol. 2:203-215.

Cardoza, Y.J. 1998. Resistance of squash silverleaf disorder and oviposition site selection by Bemisia argentifolii in Cucurbita pepo L. MS thesis. Univ. Fla., Gainesville.

Cardoza, Y.J., H.J. McAuslane, and S.E. Webb. 1999. Mechanisms of resistance to whitefly-induced squash silverleaf disorder in zucchini. J. Econ. Entomol. 92:700-707.

Chatterjee, M., S. Sparvoli, C. Edmunds, P. Garosi, K. Findlay, and C. Martin. 1996. DAG, a gene required for chloroplast differentiation and palisade development in Antirrhinum majus. EMBO J. 15:4194-4207.

Cohen, S., J.E. Duffus, and H.Y. Liu . 1992. A new Bemisia tabaci biotype in the southwestern United States and its role in silverleaf of squash and transmission of lettuce infectious yellows virus. Phytopathology 82:8690.

Costa, H.S. and J.K. Brown. 1991. Variation in biological characteristics and esterase patterns among populations of Bemisia tabaci, and the association of one population with silverleaf symptominduction. Entomol. Expt. Appl. 61:211-219.

Costa, H.S., D.E. Ullman, M.W. Johnson, and B.E. Tabashnik. 1993. Squash silverleaf symptoms induced by immature, but not adult, Bemisia tabaci. Phytopathology 83:763-766.

Dale, J.E. and F.L. Milthorpe. 1983. General features of the production and growth of leaves, p. 151-178. In: J.E. Dale and F.L. Milthorpe (eds.). The growth and functioning of leaves. Cambridge Univ. Press, New York.

Hiebert, E., A.M. Abouzid, and J.E. Polston. 1995. Whitefly-transmitted geminiviruses, p. 277-288. In: D. Gerling and R.T. Mayer(eds.). Bemisia 1995: Taxonomy, biology, damage, control, and management. Intercept, Andover, U.K.
Isebrands, J.G. and P.R. Larson. 1973. Anatomical changes during leaf ontogeny in Populus deltoides. Amer. J. Bot. 60:199-208.

Jeffree, C.E., J.E. Dale, and S.C. Fry. 1986. The genesis of intercellular spaces in developing leaves of Phaseolus vulgaris L. Protoplasma 132:90-98.

Jimenez, D.R., J.P. Shapiro, and R.K. Yokomi. 1994. Biotype-specific expression of dsRNA in the sweetpotato whitefly. Entomol. Expt. Appl. 70:143-152.

Jimenez, D.R., R.K. Yokomi, R.T. Mayer, and J.P. Shapiro. 1995. Cytology and physiology of silverleaf whitefly-induced squash silverleaf. Physiol. Mol. Plant Pathol. 46:227-242.

Keddie, J.S., B. Carroll, J.D.G. Jones, and W. Gruissem. 1996. The DCL gene of tomato is required for chloroplast development and palisade cell morphogenesis in leaves. EMBO J. 15:4208-4217.

Laurema, S. and P. Nuorteva. 1961. On the occurrence of pectin polygalacturonase in the salivary glands of Heteroptera and Homoptera Auchenorrhyncha. Annales Entomol. Fennici. 27:89-93.

Lin, T.-B., A. Schwartz, and Y. Saranga. 1999. Photosynthesis and productivity of cotton under silverleaf whitefly stress. Crop Sci. 39:174184.

McAuslane, H., S.E. Webb, and G.W. Elmstrom. 1996. Resistance in germplasm of Cucurbita pepo to silverleaf, a disorder associated with Bemisia argentifolii (Homoptera: Aleyrodidae). FloridaEntomol.79:206221.

Paris, H.S., H. Nerson, and Y. Burger. 1987. Leaf silvering of Cucurbita. Can. J. Plant Sci. 67:593-598.

Perring, T.M., A.D. Cooper, R.J. Rodriguez, C.A. Farrar, and T.S. Bellows, Jr. 1993. Identification of a whitefly species by genomic and behavioral studies. Science 259:74-77.

Ramos L.J., N. Bharathan, R.T. McMillan, Jr., and K.R. Narayanan. 1995. Histopathological changes associated with silverleaf syndrome in squash. Plant Pathol. 44:316-324.

Reiter, R.S., S.A. Coomber, T.M. Bourett, G.E. Bartley, and P.A. Scoinik. 1994. Control of leaf and chloroplast development by the Arabidopsis gene pale cress. Plant Cell 6:1253-1264.

Schuster,D.J.,J.B. Kring, and J.F.Price. 1991. Association of the sweetpotato whitefly with a silverleaf disorder of squash. Hort. Sci. 26:155-156.

Shapiro, J.P. 1995. Insect-plant interactions and expression of disorders induced by the silverleaf whitefly, Bemisia argentifolii, p. 167-177. In: D. Gerling and R.T Mayer (eds.). Bemisia 1995: Taxonomy, biology, damage, control, and management. Intercept, Andover, U.K.

Simons, J.N., P.J. Stoffella, K.D. Shuler, and R.N. Raid. 1988. Silver-leaf of squash in South Florida. Proc. Fla. State. Hort. Soc. 101:397-399.

Turgeon, R. and J.A. Webb. 1973. Leaf development and phloem transport in Cucurbita pepo: Transition from import to export. Planta 113:179_ 191.

Turgeon, R. and J.A. Webb. 1975. Leaf development and phloem transport in Cucurbita pepo: Carbon economy. Planta 123:53-62.

van de Ven, W. T. G., C. S. LeVesque, T. M. Perring, and L. L. Walling. 2000. Local and systemic changes in squash gene expression in response to silverleaf whitefly feeding. Plant Cell 12:1409-1423.

Yokomi, R.K., K.A. Hoelmer, and L.S. Osborne. 1990. Relationships between the sweetpotato whitefly and the squash silverleaf disorder. Phytopathology 80:895-900.

Yokomi, R.K., D.R. Jimenez, L.S. Osborne, and J.P. Shapiro. 1995. Comparison of silverleaf whitefly-induced and chlormequat chlorideinduced leaf silvering in Cucurbita pepo. Plant Dis. 79:950-955. 